\title{
Persistence of chloroquine-resistant haplotypes of Plasmodium falciparum in children with uncomplicated Malaria in Lagos, Nigeria, four years after change of chloroquine as first-line antimalarial medicine
}

\author{
Oladosu O Oladipo ${ }^{1}$, Oyibo A Wellington ${ }^{1 *}$ and Colin J Sutherland ${ }^{2}$
}

\begin{abstract}
Background: In Nigeria, despite the change in National malaria drug policy to artemisinin combination therapy (ACT) in 2005 due to widespread chloroquine resistance, chloroquine (CQ) is still widely used in the treatment of malaria because it is cheap, affordable and accessible. The use of ACT for the management of uncomplicated malaria is currently being promoted. The employment of genetic markers to track circulating chloroquine-resistant parasites are useful in elucidating likely poor efficacy of chloroquine, especially in settings where it is not recommended for the treatment of uncomplicated falciparum malaria. This study determined the prevalence of pfcrt haplotypes and point mutations in pfmdr 1 genes four years after the change in antimalarial treatment policy from CQ to the ACTs in Lagos, a commercial city in South-West, Nigeria.

Methods: This was a cross sectional study on uncomplicated malaria in children less than 12 years that presented with fever and other symptoms suggestive of malaria. Parasite DNA was extracted from 119 patients out of 251 children who were positive for Plasmodium falciparum by microscopy and amplified. The occurrence of haplotypes was investigated in pfcrt gene using probe-based $\mathrm{QPCR}$ and single nucleotide polymorphisms in pfmdr 1 gene using nested PCR.

Results: One hundred and nine (109) of the 119 children with P falciparum infection (91.6\%) harbourd parasites with the mutant pfcrt haplotype (CVIET). Out of this, 4.2\% comprised a mixture of genotypes encoding CVMNK and CVIET, while $4.2 \%$ had the wild type (CVMNK). Furthermore, the frequency of point mutations in pfmdr1 was $62.2 \%$ and $69.0 \%$ for codons Y86 and F184 respectively. There were no mutations at codons 1034, 1042 and 1246 of the Pfmdr1 genes.

Conclusion: The high frequency of the CQ-resistant haplotypes (CVIET) and mutations in Pfmdr1 associated with CQ resistance in P. falciparum among these children suggest that CQ-resistant parasites are still in circulation. Continuous use of chloroquine may continue to increase the level of mutations in pfcrt and pfmdr1genes. There is need to strengthen current case management efforts at promoting ACT use as well as urgently restricting access to chloroquine by the National drug regulatory agency, National Agency for Food Drug Administration and Control (NAFDAC).

(Continued on next page)
\end{abstract}

\footnotetext{
*Correspondence: wellao@yahoo.com

'ANDI Centre of Excellence for Malaria Diagnosis/WHO-FIND Malaria Specimen Collection Site, College of Medicine, University of Lagos, P.M.B 12003, Idiaraba, Lagos, Nigeria

Full list of author information is available at the end of the article
} 
(Continued from previous page)

Virtual Slides: The virtual slide(s) for this article can be found here: http://www.diagnosticpathology.diagnomx.eu/vs/ 2069472010142303

Keywords: Chloroquine, Pfcrt, Pfmdr1, Mutations, Haplotypes, Chloroquine-resistant Plasmodium falciparum, Artemesinin combination therapies (ACTS)

\section{Background}

The malaria parasite Plasmodium falciparum is one of the major causes of morbidity and mortality in subSaharan African countries, especially in children and pregnant women. Many factors have contributed to the development and spread of drug resistance, including gene mutations and drug pressure [1]. Resistance to chloroquine (CQ), the most widely used and affordable antimalarial drug, has contributed to the increased in mortality and morbidity caused by $P$. falciparum infections in endemic areas [2]. Resistance to chloroquine, the cheapest and most widely available anti-malarial, has reached significantly high levels leading to replacement with artemisinin-based combination therapy (ACT) in many malaria-endemic countries [3].

Molecular genotyping and characterization of mutations for single nucleotide polymorphism (SNPs) have been used for drug resistance monitoring and could predict emerging or existing drug resistance patterns. Genetically, chloroquine and amodiaquine resistance has been linked to $P$. falciparum chloroquine resistance transporter $(P f c r t)$ gene from different parts of the world [4-7], as well as mutations in P. falciparum multidrug resistance 1 (Pfmdr1) [8,9].

Polymorphisms in the Pfmdr1 gene have been shown by transfection to modulate higher levels of chloroquine resistance and to affect mefloquine, halofantrine, and quinine resistance [10-12]. The role played by Pfmdr1 mutations (N86Y, Y184F, S1034C and D1246Y) in mediating in vivo and in vitro chloroquine resistance has received a lot of research interest [13-15]. It has been reported that mutations in the region of Pfcrt encompassing codons $72-76$ is a key marker of $P$. falciparum chloroquine resistance [16]. Substitutions in the wild type allele, encoding CVMNK, give rise to several resistant variants, of which the most common are CVIET in South-East Asia and Africa and SVMNT, which has been reported in South America [4] and Asia [17], but rarely in Africa [18]. The change in single codon of Pfcrt gene from Lys $(\mathrm{K})$ to Thr $(\mathrm{T})$ at position $76(\mathrm{~K} 76 \mathrm{~T})$ thus is reported to play a decisive role in conferring resistance to chloroquine [4]. Prolonged use of chloroquine monotherapy has imposed high selection pressure, leading to a substantial increase in the prevalence of this marker in parasite populations worldwide.

In Nigeria, despite the change in National malaria drug policy to ACT because of the widespread and high- level clinical failure rate of chloroquine, CQ is still widely used in the treatment of malaria in the country [19], because it is accessible and affordable. Previous studies have reported resistance to chloroquine by a change at position 76 (K76T) in children treated with chloroquine in Lagos, just before the change in policy [20], in Ibadan [21] and in Osogbo [22]. However, in the above studies, CQ was still the first-line antimalarial medicine before a change in policy to ACTs and the children were treated with chloroquine. The studies did not also provide expanded haplotype information on single nucleotide polymorphisms (SNPs). Therefore, this study was carried out to elucidate single nucleotide polymorphisms in Pfcrt and the point mutations in Pfmdr1 genes with the aim of determining the status of CQ-resistant Plasmodium falciparum genes in a diverse and highly populated setting in Lagos, Nigeria, in the light of reports on return of CQ sensitive (wild type) parasites in Malawi and Kenya [23,24] after the total removal of CQ from the population.

\section{Methods}

\section{Study area/sites}

This study was conducted at the St. Kizito Primary Health Centre, Lekki, and Massey Street Children's Hospital Lagos Island, Lagos State, Southwestern Nigeria - a holoendemic area for malaria. Massey children's clinic attends to outpatients and serves as a referral paediatric centre in Lagos Metropolis. Lagos State is a commercial area with a diverse population of over 20 million people drawn from other states of Nigeria and West Africa. Lagos is located between latitude and longitude; $6^{\circ} 35^{\prime} \mathrm{N}$ $3^{\circ} 20^{\prime} \mathrm{E}$ with an altitude of $40 \mathrm{~m}(131 \mathrm{ft})$. The average temperature is $26.4^{\circ} \mathrm{C}\left(80^{\circ} \mathrm{F}\right)$ while the range of average monthly temperatures is $29^{\circ} \mathrm{C}$ to $35^{\circ} \mathrm{C}$. Mean relative humidity for an average year is recorded as $84.7 \%$ and on a monthly basis it ranges from $80 \%$ in March to $88 \%$ in June, July, September and October [25].

\section{Study population}

This research was part of a larger cross-sectional study on uncomplicated malaria in febrile children that was conducted between July 2007 and April 2008. Blood samples were collected through finger pricks from 1,211 febrile children (0-12 years) attending the outpatient clinics in both facilities. Thin and thick blood films were 
prepared and blood drops were spotted on Whatman filter papers. Parasite DNAs were extracted from a cohort of those that were positive by microscopy.

\section{Malaria microscopy}

This was the first step needed to select the dry blood spots in filter paper for the genetic analysis. Consent was obtained from the Parents/Guardian of the children before they were enrolled. Briefly, thick and thin smears were made on the same slide for each child from finger prick using a sterile lancet. Two slides were made for each child. The first slide was the read "(R)" slide (that is the slide that was read), while the other slide was archived "(A)" slide. This is in line with the quality assurance process of the ANDI Centre of Excellence for Malaria Diagnosis, College of Medicine, University of Lagos to ascertain the children who were positive with Plasmodium falciparum. Standard malaria microscopy protocol was used in staining the prepared slides. Parasitaemia levels were obtained from thick smears by counting the number of asexual parasites against 500 leucocytes and expressed per micro liter of blood using an assumed leukocyte count of $8000 \mathrm{wbc} / \mathrm{ul}$. All patients studied received appropriate standard of care after their blood was examined.

\section{Extraction of DNA from samples collected on filter paper}

Parasite genomic DNA was extracted from dried filterpapers using the Chelex 100 method according to methods described elsewhere [26]. Briefly, the discs were lysed in $5 \%$ saponin in $1 \times$ PBS and incubated at $37^{\circ} \mathrm{C}$ overnight. The samples were centrifuged, saponin and debris were removed using a vacuum pump, and the pellets washed twice in buffered saline. The samples were then suspended in 6\% Chelex 100 resin and heat-sealed in deep 96-well plates. The samples were incubated in boiling water for 20-25 minutes and then centrifuged to remove resin. Approximately $100 \mu \mathrm{l}$ of supernatant containing DNA was removed and stored at $-20^{\circ} \mathrm{C}$.

\section{Genotyping of the Pfcrt locus using qPCR}

Double-labelled probes were designed to detecthaplotypes at codons 72 to 76 of the Pfcrt gene. Each probe was dual-labelled with a reporter dye at the $5^{\prime}$ end and a quencher moiety at the $3^{\prime}$ end. This method have been previously described using this assay for Pfcrt genotyping in the UK $[17,27,28]$. Briefly, Pfcrt DNA was amplified from each sample using previously described conditions and the amplification primers Pfcrt F (TGG TAA ATG TGC TCA TGT GTT T) and Pfcrt R (AGT TTC GGA TGT TAC AAA ACT ATA GT) [27]. Amplification was performed in a Corbett Rotorgene 3000 (Corbett, Sydney, Australia) in the presence of each of the three double-labelled probes, representing the wild-type and the two most common resistance-associated haplotypes at codons $72-76$ of $P f c r t$. The probes were crt76CVMNK wild-type, 5'FAM-TGT GTA ATG AAT AAA ATT TTT GCT AA-BHQ1 (3D7 DNA from MR4 used as a positive control); crt76CVIET resistant, 5'JOE-TGT GTA ATT GAA ACA ATT TTT GCT AA-BHQ1 (Dd2 DNA from MR4 used as a positive control); and crt76SVMNT resistant, 5'ROX-AGT GTA ATG AAT ACA ATT TTT GCT AA-BHQ2 (7G8 DNA from MR4 used as a positive control). The control parasite DNA was obtained directly from The Malaria Research and Reference Reagent Resource (MR4, Manassas, Vermont, USA). Samples were considered positive for a particular genotype if a CT (threshold cycle) value of 35 cycles or fewer was obtained in at least two independent PCR experiments. Nuclease-free water was included as a negative control.

\section{Pfmdr1 genotyping}

Amplification of the Pfmdr1 gene was performed in three fragments (FR1, FR3 and FR4). Primers and cycling conditions used for the three fragments are listed in Table 1. These samples were amplified using Nested PCR reactions. In each reaction, appropriate known positive (Dd2, 7GB and FCR3) and negative samples (DNA negative wells on each row) were used.

The Pfmdr1 PCR products of nested reactions were separated by gel electrophoresis on a $1.2 \%$ agarose gel stained with ethidium bromide to identify amplified bands of DNA under ultra-violet illumination. Amplicons from nested PCR products were purified using ExoSap IT reaction [29] and were sent for sequencing. Sequencing was performed using the BigDye 3.1, Cycle Sequencing Kit (Applied Biosystems, UK) using conditions and sequencing primer pairs described elsewhere $[26,30]$. The sequence of amplified DNA products was determined using ABI PRISM 3730 Genetic Analyser (Applied Biosystems, UK). Chromas software (Technelysium, Australia) and was used to analyse the sequence results. The DNA sequence was compared with reference sequence of the Pfmdr1, portions of the P. falciparum 3D7 clone using BLAST similarity alignment (Washington University, USA). In each reaction, appropriate control DNA samples with known Pfmdr1 sequences were used in parallel with field-collected parasite isolates in every step of the protocol.

\section{Results}

A total of 1,211 children were screened in this study. The children tested included 658 (54.4\%) males and 553 (45.6\%) females; mean age \pm SD was $2.65 \pm 2.83$; while their mean body temperature was $37.8^{\circ} \mathrm{C}$ (range, 35.5$\left.42^{\circ} \mathrm{C}\right)$. Out of the total children $(<12$ years $)$ tested, 251 (20.7\%) were positive for malaria parasites by 
Table 1 Pfmdr1 PCR primer sequences and reaction conditions used in Fragments 1, 3 and 4 amplification reactions

\begin{tabular}{|c|c|c|c|c|c|}
\hline Gene fragment & Primer name & & Primer sequence & Codons & PCR cycling conditions \\
\hline \multicolumn{6}{|l|}{ Fragment 1} \\
\hline \multirow[t]{2}{*}{ Primary FR1 } & $\mathrm{FN} 1 / 1$ & $\mathrm{~F}$ & 5'- AGGTTGAAAAAGAGTTGAAC-3' & 86,184 & $94^{\circ} \mathrm{C} 3 \mathrm{~min} /\left[94^{\circ} \mathrm{C} 30 \mathrm{~s}-45^{\circ} \mathrm{C} 60 \mathrm{~s} 72^{\circ} \mathrm{C} 60 \mathrm{~s}\right]$ \\
\hline & $\mathrm{REV} / \mathrm{Cl}$ & $\mathrm{R}$ & 5'- ATGACACCACAAACATAAAT-3' & & $\times 30$ cycles \\
\hline \multirow[t]{2}{*}{ Nested FR1 } & MDR2/1 & $\mathrm{F}$ & 5'- ACAAAAAGAGTACCGCTGAAT -3' & & $72^{\circ} \mathrm{C}$ for 5 minutes $/ 15^{\circ} \mathrm{C} 5 \mathrm{~min}$ \\
\hline & NEWREV1 & $\mathrm{R}$ & 5'-AAACGCAAGTAATACATAAAGTC-3' & & \\
\hline \multicolumn{6}{|l|}{ Fragment 3} \\
\hline \multirow[t]{2}{*}{ Primary FR3 } & MDRFR3N1 & $\mathrm{F}$ & 5'-GCATTTATAATATGCATACTG-3' & 1034,1042 & $94^{\circ} \mathrm{C} 3 \mathrm{~min} /\left[94^{\circ} \mathrm{C} 30 \mathrm{~s}-55^{\circ} \mathrm{C} 60 \mathrm{~s} 65^{\circ} \mathrm{C} 40 \mathrm{~s}\right]$ \\
\hline & MDRFR3R1 & $\mathrm{R}$ & 5'-GGATTTCATAAAGTCATCAAC-3' & & $\times 30$ cycles \\
\hline \multirow[t]{2}{*}{ Nested FR3 } & MDRFR3N2 & $\mathrm{F}$ & 5'-GGTTTAGAAGATTATTTCTGTA-3' & & $72^{\circ} \mathrm{C} 5 \mathrm{~min} / 15^{\circ} \mathrm{C} 5 \mathrm{~min}$ \\
\hline & MDRFR3R1 & $\mathrm{R}$ & 5'-GGATTTCATAAAGTCATCAAC-3' & & \\
\hline \multicolumn{6}{|l|}{ Fragment 4} \\
\hline \multirow[t]{2}{*}{ Primary FR4 } & MDRFR4N1 & $\mathrm{F}$ & 5'- CAAACCAATCTGGATCTGCAGAAG -3' & 1246 & $94^{\circ} \mathrm{C} 3 \mathrm{~min} /\left[94^{\circ} \mathrm{C} 30 \mathrm{~s}-55^{\circ} \mathrm{C} 60 \mathrm{~s}-65^{\circ} \mathrm{C} 40 \mathrm{~s}\right]$ \\
\hline & MDRFR4R1 & R & 5'-CAATGTTGCATCTTCTCTTCC -3' & & $\times 30$ cycles \\
\hline \multirow[t]{2}{*}{ Nested FR4 } & MDRFR4N2 & $\mathrm{F}$ & 5'- GATCTGCAGAAGATTATACTG -3' & & $72^{\circ} \mathrm{C} 5 \mathrm{~min} / 15^{\circ} \mathrm{C} 5 \mathrm{~min}$ \\
\hline & MDRFR4R1 & $\mathrm{R}$ & 5'- CAATGTTGCATCTTCTCTTCC -3' & & \\
\hline
\end{tabular}

FR - Fragment F - forward R - Reverse.

NB: Cycling conditions are the same for primary and nested PCRs.

microscopy. Parasite DNAs were successfully obtained from a cohort of 251 microscopy positive malaria parasites samples during extraction.

\section{Pfcrt polymorphisms}

A total of 119 DNA samples were successfully tested for Pfcrt genotype at codons 72-76. Most of the isolates (91.6\%) harboured parasites with the CVIET haplotypes. The proportion of the wild type (CVMNK) among the isolates was $4.2 \%$, while mixed haplotype infections (CVMNK/CVIET) were found in 5 isolates (4.2\%) (Table 2). The Southeast Asian/South American chloroquine-resistant haplotype (SVMNT) was not seen in any of the isolates.

\section{Pfmdr1 polymorphisms}

The isolates were genotyped for Pfmdr1 at codons 86, 184, 1034, 1042 and 1246. The majority of isolates had the mutant Pfmdr1 Y86 and F184 alleles. Of the isolates, $62.2 \%(46 / 74)$ carried the mutant allele Y86 and 69\% (49/71) and had the mutant allele F184 (Table 2). There was no mutation in codons 1034, 1042 and 1246 in any isolates.

\section{Discussion}

Self-treatment with chloroquine and other monotherapies are still high in the population because of their affordability, accessibility, and low implementation of the malaria treatment guidelines that recommends the use of ACTs. The access to, and high usage of CQ and other monotherapies in the treatment of malaria makes the determination of chloroquine resistant Plasmodium falciparum in Lagos imperative several years after the change in malaria treatment policy. CQ is still sold especially in the informal private sector among the Private Propriety Medicine Vendors (PPMVs), otherwise known as medicine retailers, a group that provide malaria treatment to over $60 \%$ of fever patients in the country.

Table 2 Pfcrt haplotypes and frequency of Pfmdr 1 codons in Nigerian children

\begin{tabular}{llll}
\hline Gene & $\mathbf{n}$ & Genotype/haplotype & Prevalence (\%) \\
\hline Pfcrt & 119 & CVIET (mutant type) & $109(91.6)$ \\
Amino acids (72-76) & & CVMNK (wild type) & 5 (4.2) \\
& & CVMNK/CVIET (mixed) & $5(4.2)$
\end{tabular}

Pfmdr1

\begin{tabular}{|c|c|c|c|}
\hline \multirow{12}{*}{$\begin{array}{l}\text { Amino acids } 86,184, \\
1034,1042 \text { and } 1246\end{array}$} & 74 & 86Y (mutant type) & $46(62.2)$ \\
\hline & & 86 N (wild type) & $14(18.9)$ \\
\hline & & $86 \mathrm{~N}+86 \mathrm{Y}$ (mixed) & $14(18.9)$ \\
\hline & 71 & 184 F (mutant type) & $49(69)$ \\
\hline & & 184Y (wild type) & $11(15.5)$ \\
\hline & & $184 \mathrm{~F}+184 \mathrm{Y}($ mixed $)$ & $11(15.5)$ \\
\hline & 81 & 1034C (mutant type) & $0(0)$ \\
\hline & & 10345 (wild type) & $81(100)$ \\
\hline & 81 & 1042D (mutant type) & $0(0)$ \\
\hline & & 1042 N (wild type) & $81(100)$ \\
\hline & 29 & $1246 S$ (mutant type) & $0(0)$ \\
\hline & & 1246D (wild type) & $29(100)$ \\
\hline
\end{tabular}


Further, the PPMVs sell antimalarial medicines on the basis of their clients' complaints and are not permitted to do a blood based test due to policy restrictions.

Mutations in the region of Pfcrt codons $72-76$ is said to be a key marker of $P$. falciparum chloroquine resistance [16]. This study showed high prevalence of Pfcrt CVIET haplotype (72-76). This result is consistent with previous study where majority (98\%) of the isolates genotyped carried the chloroquine resistant CVIET haplotype in Uganda [31] and in Swaziland [32]. Persistence of high prevalence of CVIET was also reported in Ethiopia due the continuous use of chloroquine for the treatment of P. vivax [33]. This study showed that the SVMNT haplotype does not occur in Lagos, Nigeria. The absence of the SVMNT haplotype which is known to occur majorly in South America is consistent with many other reports in Africa [16,32] except studies in part of East Africa (Tanzania and Angola)that reported SVMNT $[18,34]$. This was presumed to be as a result of $P$. falciparum resistance to amodiaquine or its metabolite desethyl-amodiaquine following the use of amodiaquine as monotherapy.

The present study showed prevalence of $62.2 \%$ and 69.0\% for Pfmdr1 Y86 and F184 (mutant-type) respectively. The role of Pfmdr1 gene mutations in antimalarial drugs resistance is still controversial. An in vivo study where a chloroquine-resistant infection was reported showed absence of mutations at codons Pfmdr1 86 and 1246 in the [35,36]. Similarly, a study in SouthEastern Iran reported a strong association between $p f c r t$ K76T, but not pfmdr1 N86Y mutation and in vivo chloroquine resistance [37]. A study in Haiti reported mutation in F184 only in the Pfmdr1 gene and no mutation was seen in Pfcrt gene codon 72-76 [38]. In contrast, Y86 have been reported to be responsible for chloroquine resistance in combination with Pfcrt $76 \mathrm{~T}$ [13,21,39] and another study from Madagascar reported an association between Pfmdr1 Y86 mutant alleles and chloroquine clinical resistance with no such association with Pfcrtgene [40]. Polymorphisms in the Pfmdr1 gene have been said to be under artemether-lumenfantrine selection pressure [41]. Selection of Pfmdr1 Y86by amodiaquine and chloroquine were reported previously in the Gambia [42], and in Kenya [43]. Thus, the success of treatment with ACTs may largely depend on the parasite's existing level of tolerance to the partner drugs.

Some earlier studies in the pre-ACT days in SouthWest Nigeria reported high chloroquine-resistant parasites in children treated with CQ when CQ was the drug of choice for the treatment of malaria and they only determined mutation at position 76 (K76T). Mutation at 76 (K76T) had been reported to play a decisive role in conferring resistance to CQ [4]. In a semi-urban area of Lagos, South-West Nigeria, the prevalence of T76 mutation was $74.6 \%$ [20], while another study In Ibadan; South-West Nigeria reported 62\% and 29\% for T76 and Y86 mutations respectively [21]. Prevalence of $74 \%, 29 \%$ and $64 \%$ were reported for mutations at T76, Y86 and F184 respectively in children with $P$. falciparum even before they were treated in Osogbo, South-West Nigeria while in another study in Ibadan (south-West Nigeria), a prevalence of $60 \%, 33 \%$ and $14 \%$ mutations at T76, Y86 and F184 respectively was reported in children whose age ranged from 6 month - 12 years [44]. Also another study in Ogun State, still in the South-West zone of Nigeria, reported a prevalence of $96.9 \%$ at $\mathrm{K} 76 \mathrm{~T}$ among children under the age of five years [45].

Our study in Lagos, South-West Nigeria, has showed the persistence of chloroquine-resistant parasites circulating in children four years after the change in policy for the treatment of uncomplicated malaria from CQ to ACTs. It is therefore important that apart from the change in policy to ACTs, there is an urgent need to restrict the use of chloroquine in the general population by the regulatory agency for drugs. Since resistant phenotypes often have fitness costs [46], their prevalence is likely to decline after removal of the selective pressure. In countries where the change in policy from chloroquine to ACT was strictly enforced, marked decrease in chloroquine-resistant parasites in the population was recorded. In a recent surveillance study in Honduras, Central America, where CQ is still used for the management of uncomplicated malaria, all the samples tested showed CQ susceptibility in the Pfcrt "CVMNK" genotype in codons 72-76 [47].

There was a decrease in the frequency of Pfcrt76T mutation when CQ was abolished in the treatment of $P$. falciparum malaria in the People's Republic of China [48]; prevalence of mutant alleles of Pfcrt76T decreased from $64.5 \%$ in 2002 to $16 \%$ in 2004 and that of the mutant Pfmdr1 $86 \mathrm{Y}$ alleles decreased from $46.6 \%$ to $2.7 \%$ two and half years after successful withdrawal of CQ in coastal Tanzania [49]. It was also reported that the prevalence of the CQ-resistant Pfcrt76T genotype decreased from 85\% in 1992 to $13 \%$ in 2000 in Malawi [49]. In 2001, CQ cleared $100 \%$ of 63 asymptomatic $P$. falciparum infections as no isolates were resistant to CQ in vitro, and no infections with the CQ resistant $P f c r t 76 \mathrm{~T}$ genotype were detected [50]. Similarly, it was shown that CQ was again an efficacious treatment for malaria, 12 years after it was successfully withdrawn from use in Malawi [23]. Similar result was also reported in Kenya where the frequency of the Pfcrt-76 mutant significantly decreased from around 95\% to 60\%, though, the frequency of Pfmdr1-86 did not decline substantially [24]. In Tanzania, where chloroquine is no longer in use, the frequency of the wild type CVMNK haplotype increased from 6\% in 2003 to 30\% in 2007. These findings may reflect decreasing drug pressure of chloroquine on the parasite populations in these areas. 
Surveillance for antimalarial drug resistance, using the platform provided by the National Malaria control Programme in Nigeria should be supported to undertake regular and robust monitoring of malaria parasite resistance genes for trends. The use of amodiaquine has been associated to a certain extent with Pfcrt76T and Pfmdr1 $86 \mathrm{Y}$ mutations $[21,43]$. Furthermore, the partner drugs to $\mathrm{ACT}$ are also threatened by the development of resistance if treatment of malaria with antimalarial monotherapy is not abolished [51,52]. Importantly, the implementation of the current malaria treatment policy using the ACTs should be strengthened, vigorously promoted, through regular training, supervision among health workers; and the institution of best procurement practices for malaria medicines at all levels based on National Policy recommendations. The regulatory agency, National Agency for Food Drug Administration and Control (NAFDAC) should regulate access to chloroquine in Nigeria while the general public should be enlightened on the high levels of circulating resistant-malaria parasite genes to chloroquine, its low efficacy and to discourage its continuous use for the for the treatment of uncomplicated malaria. Access to ACTs should be expanded and made affordable especially in the private sector where a high number of persons with fever are treated.

\section{Conclusion}

There is a high level of CQ-resistant-haplotypes of P. falciparum (CVIET) and high frequency of mutations in Pfmdr1 four years after the change in malaria treatment policy from CQ to ACTs for the treatment of uncomplicated malaria in Lagos, South-western Nigeria. This suggests persistent circulation and spread of CQresistant $P$. falciparum parasites in the population and the need to strengthen current efforts at promoting ACT use in the treatment of uncomplicated malaria. The continued use of CQ for the treatment of malaria in Nigeria could be one major reason for the persistence of mutant Pfcrt haplotypes and Pfmdr1 mutations in the study area. This could threaten the efficacy of partner drugs in the ACTs. Data from this study provided evidence of continued CQ use and the need for the key players in the Federal Ministry of Health to decisively regulate the use of CQ in Nigeria.

\section{Ethical approval}

This study was approved by The Research, Grants and Experimentation Committee, of the College of Medicine, University of Lagos, Idi-Araba, Lagos, Nigeria and the Research Ethics Committee of the Lagos University Teaching Hospital, Idi-Araba Lagos, Nigeria.

\section{Abbreviations}

CQ: Chloroquine; ACT: Artemisinin combination therapy; Pfcrt: Plasmodium falciparum chloroquine resistant transporter; Pfmdr 1: Plasmodium falciparum multidrug resistant; PPMVs: Private Propriety Medicine Vendors; qPCR: Quantitative polymerase chain reaction; DNA: Deoxyribonucleic acid; CT: Threshold cycle.

\section{Competing interests}

The authors declare that they have no competing interests.

\section{Authors' contributions}

○० participated in sample collection and processing, carried out the molecular genetic analyses and drafted the manuscript. OW conceived the study, participated in the design of the study and coordination and helped to draft the manuscript. CJ provided the platform for molecular analysis, the reagents used and contributed immensely to the molecular genetic studies and in drafting the paper. All the authors read and approved the final manuscript.

\section{Acknowledgement}

We acknowledge the support of the management and staff of St. Kizito and Massey Children's Hospital in providing the platform for assessing the patients in this study. In addition, we thank the parents/Guardians of the children for allowing their children/wards to participate in the study. Finally, we thank post-doctoral and pre-doctoral fellows in the laboratory of Dr. Colin Sutherland who contributed to the development of techniques used in the molecular elucidation of this study. Finally, we thank WHO/ TDR and FIND for supporting the development of the ANDI Centre of Excellence for Malaria Diagnosis that was deployed in the initial analyses of this study.

\section{Author details}

${ }^{1}$ ANDI Centre of Excellence for Malaria Diagnosis/WHO-FIND Malaria Specimen Collection Site, College of Medicine, University of Lagos, P.M.B 12003, Idiaraba, Lagos, Nigeria. ${ }^{2}$ Faculty of Infectious and Tropical Diseases, London School of Hygiene and Tropical Medicine, London, UK.

Received: 11 September 2014 Accepted: 16 April 2015

Published online: 28 April 2015

\section{References}

1. Talisuna AO, Nalunkuma-Kazibwe A, Langi P, Mutabingwa TK, Watkins WW, Van Marck E, et al. Two mutations in dihydrofolatereductase combined with one in the dihydropteroate synthase gene predict sulphadoxine-pyrimethamine parasitological failure in Ugandan children with uncomplicated falciparum malaria. Infect Genet Evol. 2004;4:321-7.

2. WHO. Guidelines for the treatment of malaria. 2nd ed. Geneva: World Health Organization; 2010.

3. WHO. Antimalarial drug combination therapy: report of a WHO technical consultation. Geneva, Switzerland: World Health Organization; 2001.

4. Fidock DA, Nomura T, Talley AK, Cooper RA, Dzekunov SM, Ferdig MT, et al. Mutations in the $P$. falciparum digestive vacuole transmembrane protein PfCRT and evidence for their role in chloroquine resistance. Mol Cell. 2000;6:861-71.

5. Chen N, Kyle DE, Pasay C, Fowler EV, Baker J, Peters JM, et al. Pfcrt allelic types with two novel amino acid mutations in chloroquine-resistant Plasmodium falciparum isolates from the Philippines. Antimicrob Agents Chemother. 2003:47:3500-5.

6. Djimde AA, Doumbo OK, Traore O, Guindo AB, Kayentao K, Diourte Y, et al. Clearance of drug-resistant parasites as a model for protective immunity in Plasmodium falciparum malaria. Am J Trop Med Hyg. 2003;69:558-63.

7. Ursing J, Kofoed PE, Rodrigues A, Rombo L, Gil JP. Plasmodium falciparum genotypes associated with chloroquine and amodiaquine resistance in Guinea-Bissau. Am J Trop Med Hyg. 2007;76:844-8.

8. Foote SJ, Thompson JK, Cowman AF, Kemp DJ. Amplification of the multidrug resistance gene in some chloroquine-resistant isolates of P. falciparum. Cell. 1999;57:921-30.

9. Hayward R, Saliba KJ, Kirk K. Mutations in pfmdr1 modulate the sensitivity of Plasmodium falciparum to the intrinsic antiplasmodial activity of verapamil. Antimicrob Agents Chemother. 2005;49:840-2.

10. Djimde A, Doumbo OK, Cortese JF, Kayentao K, Doumbo S, Diourte Y, et al. A molecular marker for chloroquine-resistant falciparum malaria. N Engl J Med. 2001;344:257-63. 
11. Sidhu AB, Verdier-Pinard D, Fidock DA. Chloroquine resistance in Plasmodium falciparum malaria parasites conferred by Pfcrtmutations. Science. 2002;298:210-3.

12. Cheruiyot J, Ingasia LA, Omondi AA, Juma DW, Opot BH, Ndegwa JM, et al. Polymorphisms in Pfmdr1, Pfcrt, and Pfnhel genes are associated with reduced In Vitro Activities of Quinine in Plasmodium falciparum Isolates from Western Kenya. Antimic Agents Chemo. 2014;58 Suppl 7:3737-43.

13. Duraisingh MT, Cowman AF. Contribution of the pfmdr1gene to antimalarial drug resistance. Acta Trop. 2005;94:181-90.

14. Khalil IF, Alifrangis M, Tarimo DS, Staalso T, Satti GM, Theander TG. The roles of the pfcrt $76 \mathrm{~T}$ and pfmdr1 $86 \mathrm{Y}$ mutations, immunity and the initial level of parasitaemia, in predicting the outcome of chloroquine treatment in two areas with different transmission intensities. Ann Trop Med Parasitol. 2005;99:441-8.

15. Andriantsoanirina $V$, Ratsimbasoa A, Bouchier C, Jahevitra M, Rabearimanana S, Radrianjafy $R$, et al. Plasmodium falciparum drug resistance in Madagascar: facing the spread of unusual pfdhfr and pfmdr-1 haplotypes and the decrease of dihydroartemisinin susceptibility. Antimicrob Agents Chemother. 2009;53(Suppl11):4588-97.

16. Gadalla NB, Elzaki SE, Mukhtar E, Warhurst DC, El-Sayed B, Sutherland CJ. Dynamics of pfcrt alleles CVMNK and CVIET in chloroquine-treated Sudanese patients infected with Plasmodium falciparum. Malaria J. 2010;9:74.

17. Sutherland CJ, Haustein T, Gadalla N, Armstrong M, Doherty JF, Chiodini PL. Chloroquine resistant Plasmodium falciparum infections among UK travellers returning with malaria after chloroquine prophylaxis. J Ant Chem. 2007:59:1197-9.

18. Alifrangis M, Dalgaard MB, Lusingu JP, Vestergaard LS, Staalsoe T, Jensen AT, et al. Occurrence of the Southeast Asian/South American SVMNT haplotype of the chloroquine resistance transporter gene in Plasmodium falciparum in Tanzania. J Infect Dis. 2006;193:1738-41.

19. Ogungbamigbe T, Ogunro P, Elemile P, Egbewale B, Olowu O, Abiodun O. Presciption patterns of antimalarial drugs among medical practitioners in Osogbo Metropolis, South-West Nigeria. Trop Med Health. 2005;33:201-8.

20. Olukosi YA, Iwalokun BA, Magbagbeola EO, Akinwande O, Adewole TA, Agomo PU. Pattern of rural-urban aquisition of Pfcrt T76 allele among Nigerian children with uncomplicated Plasmodium falciparum malaria. Afr J Biotec. 2005;4 Suppl 4:361-6.

21. Happi CT, Gbotosho GO, Folarin OA, Bolaji OM, Sowunmi A, Kyle DE, et al. Association between mutations in plasmodium falciparum chloroquine resistance transporter and $p$. falciparum multidrug resistance 1 genes and in vivo amodiaquine resistance in $p$. falciparum malaria-infected children in Nigeria. Am J Trop Med Hyg. 2006;75 Suppl 1:155-61.

22. Ojurongbe O, Ogungbamigbe TO, Fagbenro-Beyioku AF, Fendel R, Kremsner PG, Kun JF. Rapid detection of Pfcrt and Pfmdr1 mutations in Plasmodium falciparum isolates by FRET and in vivo response to chloroquine among children from Osogbo, Nigeria. Malar J. 2007;6:41.

23. Laufer MK, Thesing PC, Eddington ND, Masonga R, Dzinjalamala FK, Takala SL, et al. Return of chloroquine antimalarial efficacy in Malawi. N Engl J Med. 2006;355:1959-66.

24. Mwai L, Ochong E, Abdirahman A, Kiara SM, Ward S, Kokwaro G, et al. Chloroquine resistance before and after its withdrawal in Kenya. Malaria J. 2009;8:106.

25. Nigerian muse Online: 7 February 2007. Available at: http://en.wikipedia.org/ wiki/Lagos. Accessed 4 April 2013.

26. Humphreys GA, Merinopoulos I, Ahmed J, Whitty CJM, Mutabingwa TK, Sutherland $\mathrm{C}$, et al. Amodiaquine and artemether-lumefantrine select distinct alleles of the Plasmodium falciparum pfmdr1 gene in Tanzanian children treated for uncomplicated malaria. Antimicrob Agents Chemother. 2007;51:991-7.

27. Sutherland CJ, Fifer H, Pearce RJ, BinReza F, Nicholas M, Haustein T, et al. Novel pfdhpshaplotypes among imported cases of Plasmodium falciparum malaria in the UK. Antimicrob Agents Chemother. 2009;53 Suppl 8:3405-10.

28. Wilson PE, Kazadi W, Kamwendo DD, Mwapasa V, Purfield A, Meshinick SR. Prevalence of pfcrt mutations in Congolese and Malawian Plasmodium falciparum isolates as determined by a new Taqman assay. Acta Trop. 2005;93:97-106.

29. Bell J. A simple way to treat PCR products prior to sequencing using ExoSAP-IT. Biotechniques. 2008;44:834.

30. Pearce RJ, Drakeley C, Chandramohan D, Mosha F, Roper C. Molecular determination of point mutation haplotypes in the dihydrofolatereductase and dihydropteroate synthase of Plasmodium falciparum in three districts of northern Tanzania. Antimicrob Agents Chemother. 2003;47:1347-54.

31. Keen J, Farcas GA, Zhong K, Yohanna S, Dunne MW, Kain KC. Real-time PCR assay for rapid detection and analysis of PfCRT haplotypes of chloroquine resistant Plasmodium falciparum isolates from India. J Clin Microbiol. 2007:45:2889-93.

32. Dlamini SV, Beshir K, Sutherland CJ. Markers of anti-malarial drug resistance in Plasmodium falciparum isolates from Swaziland: identification of pfmdr1-86 F in natural parasite isolates. Malaria J. 2010;9:68.

33. Golassa L, Enweji N, Erko B, Aseffa A, Swedberg G. High prevalence of pfcrt-CVIET haplotype in isolates from asymptomatic and symptomatic patients in south-central Oromia, Ethiopia. Malar J. 2014;13:120.

34. Gama BE, Pereira de Carvalho GA, LutucutaKosi FJ, Almeida de Oliveira NK, Fortes F, Rosenthal PJ, et al. Plasmodium falciparum isolates from Angola show the StctVMNT haplotype in the pfort gene. Malar J. 2010;9:174.

35. Basco LK, Bras JL, Rhoades Z, Wilson CM. Analysis of pfmdr1 and drug susceptibility in fresh isolates of Plasmodium falciparum from Sub-Saharan Africa. Mol Biochem Parasitol. 1995;74:157-66.

36. von Seidlein L, Duraisingh MT, Drakeley CJ, Bailey R, Greenwood BM, Pinder M. Polymorphism of the pfmdr1 gene and chloroquine resistance in Plasmodium falciparum in the Gambia. Trans R Soc Trop Med Hyg. 1997:91:450-3

37. Zakeri S, Afsharpad M, Kazemzadeh T, Mehdizadeh K, Shabani A, Djadid ND. Association of pfcrt but not pfmdr1 alleles with chloroquine resistance in Iranian isolates of Plasmodium falciparum. Am J Trop Med Hyg. 2008;78:633-40.

38. ElBadry ME, Existe A, Victor YS, Memnon G, Fukuda M, Dame JB, et al. Survey of Plasmodium falciparum multidrug resistance-1 and chloroquine resistance transporter alleles in Haiti. Malar J. 2013;12:426.

39. Nagesha HS, Din S, Casey GJ, Susanti Al, Fryauff DJ, Reeder JC, et al. Mutations in the pfmdr1, dhfrand dhps genes of Plasmodium falciparum are associated with in-vivo drug resistance in west Papua, Indonesia. Trans $\mathrm{R}$ Soc Trop Med Hyg. 2001;95:43-9.

40. Andriantsoanirina V, Ratsimbasoa A, Bouchier C, Tichit M, Jahevitra M, Rabearimanana S, et al. Chloroquine clinical failures in Plasmodium falciparum malaria are associated with mutant pfmdr-1, not pfert in Madagascar. PLoS One. 2010;5, e13281.

41. Happi CT, Gbotosho GO, Folarin OA, Sowunmi A, Hudson T, O'Neil M, et al. Selection of Plasmodium falciparum multidrug resistance gene 1 alleles in asexual stages and gametocytes by artemether-lumefantrine in Nigerian children with uncomplicated falciparum malaria. Antimic Agents Chemoth. 2009;53 Suppl 3:888-95.

42. Duraisingh MI, Drakeley Cl, Muller O, Bailey R, Snounou G, Targett GA, et al. Evidence for selection for the tyrosine 86 allele of pfmdr 1 gene of Plasmodium falciparum by chloroquine and amodiaquine. Parasitology. 1997;114:205-11.

43. Holmgren G, Gil GP, Ferreira PM, Veiga MI, Obonyo CO, Bjorkman A. Amodiaquine resistant Plasmodium falciparum malaria invivo is associated with selection of Pfcrt76T and Pfmdr1 86Y. Infect Genet Evol. 2006;6:309-14.

44. Folarin OA, Gbotosho GO, Sowunmi A, Olorunsogo OO, Oduola AMJ, Happi TC. Chloroquine resistant Plasmodium falciparum in Nigeria: relationship between pfcrtand pfmdr1 polymorphisms, In-Vitro resistance and treatment outcome. Open Trop Med J. 2008;1:74-82.

45. Efunshile M, Runsewe-Abiodun T, Ghebremedhin B, Konig W, Konig B. Prevalence of the molecular marker of chloroquine resistance (pfcrt 76) in Nigeria 5 years after withdrawal of the drug as first-line antimalarial. A cross-sectional study. SAJCH. 2011;5 Suppl 2:39-42.

46. Yang Z, Zhang Z, Sun X, Wan W, Cui L, Zhang X, et al. Molecular analysis of chloroquine resistance in Plasmodium falciparumin Yunnan Province, China. Trop Med Intl Health. 2007;12:1051-60.

47. Fontecha GA, Sanchez AL, Mendoza M, Banegas E, Mejía-Torres RE. A four-year surveillance program for detection of Plasmodium falciparum chloroquine resistance in Honduras. Memlnst Oswaldo Cruz. 2014;109(4):492-9.

48. Wang X, Um J, Li Q, Chen P, Guo X, Fu L, et al. Decreased prevalence of the Plasmodium falciparum chloroquine resistance transporter $76 \mathrm{~T}$ marker associated with cessation of choroquine use against $P$. falciparum malaria in Hainan, people's Republic of China. Am J Trop Med Hyg. 2005;72:410-4. 
49. Temu EA, Kimani I, Tuno N, Kawada H, Minjas JN, Takagi M. Monitoring chloroquine resistance using Plasmodium falciparum parasites isolated from wild mosquitoes in Tanzania. AmJ Trop Med Hyg. 2006;75:1182-7.

50. Kublin JG, Cortese JF, Njunju EM, Mukadam RA, Wirima JJ, Kazembe PN, et al. Reemergence of chloroquine-sensitive Plasmodium falciparum malaria after cessation of chloroquine use in Malawi. J Infect Dis. 2003;187:1870-5.

51. Noedl H, Se Y, Schaecher K, Smith BL, Socheat D, Fukuda MM. Artemisinin Resistance in Cambodia 1 (ARC1) Study Consortium: evidence of artemisinin-resistant malaria in western Cambodia. N Eng J Med. 2008;359:2619-20.

52. Dondorp AM, Nosten F, Yi P, Das D, Phyo AP, Tarning J, et al. Artemisinin resistance in Plasmodium falciparum malaria. N Eng J Med. 2009;361:455-67.

\section{Submit your next manuscript to BioMed Central and take full advantage of:}

- Convenient online submission

- Thorough peer review

- No space constraints or color figure charges

- Immediate publication on acceptance

- Inclusion in PubMed, CAS, Scopus and Google Scholar

- Research which is freely available for redistribution 